MEMÓRIA

\title{
A Propriedade Intelectual e a Vacina contra a Peste da Manqueira
}

\author{
Apresentação \\ Claudia Inês Chamas \\ Pesquisadora - Instituto Oswaldo Cruz, Fiocruz, Ministério da Saúde
}

Fundadas nos modelos de reputação e mérito, através da quantidade e qualidade das publicações, as universidades e instituiçốes de pesquisa contemporâneas aperfeiçoaram estratégias para divulgar aos seus pares e à sociedade, o mais rapidamente possível, suas realizações. Como afirmou Jean-Baptiste de Lamarck:" "It is not enough to discover and prove a useful truth previously unknown (...) it is necessary also to be able to propagate it and get it recognised."

A codificação (formalização) dos conhecimentos e a sua divulgação são elementos centrais na cultura acadêmica. A publicação científica constitui forma complementar ao trabalho laboratorial, criando público, disseminando informação nova, ordenando autoridade, dando crédito e estabelecendo precedências. ${ }^{2}$ Seja para cientistas da indústria ou do meio universitário, o reconhecimento da prioridade é alicerce fundamental do sistema de recompensas. Porém, é importante ressaltar que outras recompensas podem ser obtidas por meio de outros caminhos.

Desde o advento da Lei de Propriedade Industrial (Lei no 9.279/96) e da Lei de Direitos Autorais (Lei no 9.610/98), calorosos debates vêm ocorrendo na academia brasileira. Como patentear e publicar simultaneamente? Como

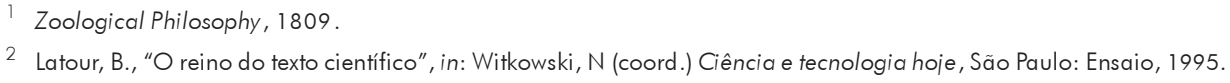


tornar compatíveis o rol de inventores da patente e a lista de autores do artigo correspondente? Como negociar os direitos de propriedade com entidades privadas? Como determinar o valor dos royalties nos contratos de licenças de patentes? Como distribuir os royalties entre as instituições e os inventores envolvidos no processo? A recém-aprovada Lei da Inovação (Lei no 10.973/04) e sua Regulamentação (Decreto n⿳0 5.563/05) tornam irreversível o processo de adaptação da academia ao complexo mundo da propriedade intelectual. Novos problemas e dimensões para a pesquisa brasileira? Nem tanto! A trajetória inicial do Instituto Oswaldo Cruz (Fiocruz) nos apresenta surpresas e ensinamentos. Jaime Benchimol menciona que, logo nos primeiros anos do século XX, Alcides Godoy, cientista do Instituto dedicava-se à produção dos soros antidiftérico e antitetânico e ao problema da peste da manqueira ${ }^{3}$ (carbúnculo sintomático), uma epizootia fatal para bezerros em muitas regiões do Brasil e em vários países da América do Sul. ${ }^{4}$ Inicialmente, o problema da peste da manqueira havia sido estudado por Ezequiel Dias e Rocha Lima, ${ }^{5}$ mas depois de 1905, Godoy tornou-se responsável pelo projeto.

Das investigações de Godoy, surgiu a notável vacina veterinária que marcou a vida em Manguinhos. A partir de uma solicitação dos pecuaristas de Minas Gerais, foi desenvolvida a vacina contra o carbúnculo sintomático. A metodologia aplicada foi bem-sucedida, permitindo a sua fabricação em escala comercial.

A experiência foi pontuada por conflitos políticos e gerenciais. Nara Britto, a partir de depoimento oral de Lobato Paraense, esclarece que as discussóes em torno desta vacina originaram divergências, gerando três posições sobre a aplicação dos lucros auferidos com a comercialização do produto. ${ }^{6}$ Oswaldo Cruz decidiu destinar os royalties da vacina aos inventores. Uma vertente apoiou a medida tomada por Oswaldo Cruz. Outro grupo pensava em aplicar as verbas em compra de materiais laboratoriais. Um terceiro grupo defendeu a distribuição eqüitativa dos lucros entre os pesquisadores, como forma de acréscimo salarial. Questionou-se também a "legitimidade de propriedade de um produto desenvolvido numa instituição pública”.

\footnotetext{
3 Também conhecida como mal do ano ou ando ou mal do quarto inchado.

4 Benchimol, J.L., "Origens e evolução do Instituto Oswaldo Cruz no período 1899-1937, in Benchimol, J.L. (coord.) Manguinhos do sonho à vida: A ciência na Belle Époque, Rio de Janeiro: Fiocruz, Casa de Oswaldo Cruz, 1990.

5 Benchimol também cita as pesquisas anteriores de J. Batista de Lacerda, que não foram frutíferas.

6 Britto, N., Oswaldo Cruz: a construção de um mito na ciência brasileira, Rio de Janeiro: Fiocruz, 1995.
} 
Em relatório do Instituto Oswaldo Cruz, de 14 de fevereiro de 1912, Oswaldo Cruz tece comentários generosos em relação à atitude de desprendimento de Godoy, posto que este havia cedido a titularidade da vacina ao Instituto. Godoy condicionou a cessão à aplicação das verbas em atividades de aquisição de livros e de publicação da revista Memórias do Instituto Oswaldo Cruz, conforme Relatório do Instituto Oswaldo Cruz, de 1911 (Britto, 1995).

A patente da vacina foi registrada em 24 de novembro de 1908 (cartapatente no 5.566, publicada no Diário Oficial, de 6 de dezembro de 1908), e lavrada pelo tabeliāo Evaristo Vale de Barros, em 11 de dezembro de 1908. O termo de cessão foi registrado em 24 de março de 1909, no livro 5, fl.132, do registro geral de privilégios, da Diretoria Geral de Indústria (Ministério da Viação e Obras Públicas). O não cumprimento das condições supracitadas invalidaria a cessão. Entendimento verbal entre Oswaldo Cruz e Alcides Godoy possibilitou o remanejamento, em favor do inventor, de $5 \%$ da renda bruta da vacina até 1917, e daí em diante, 8\% (Benchimol, 1990).

As verbas da manqueira foram vitais para o Instituto, uma vez que não eram objeto da burocracia do Ministério da Justiça e não necessitavam ser submetidas aos critérios de aplicação de recursos votados pelo Congresso. Um novo tipo de parceria público-privada emergia, então, do efervescente ambiente de Manguinhos. Os royalties permitiram também o pagamento de salários de pesquisadores e funcionários e o custeio de parte das construçōes (Benchimol, 1990).

Verdadeiras ações de marketing foram delineadas. Visando incrementar a arrecadação das vendas da vacina, esforços foram direcionados para difundir a nova tecnologia nas zonas pastoris brasileiras. À época, o Ministério da Agricultura e outros órgãos públicos estaduais ou municipais eram os responsáveis pelo fornecimento deste tipo de produto. Para superar as deficiências do sistema de distribuição, Oswaldo Cruz organizou, em 1913, uma seção de "Propaganda da Vacina contra a Peste da Manqueira", sob a responsabilidade de Eduardo Dale (Benchimol, 1990). Em 1939, Alcides Godoy e Astrogildo Machado desligaram-se do Instituto e fundaram a empresa Produtos Veterinários Manguinhos Ltda. A vacina até hoje é comercializada.

Como vimos, nada mais atual que a discussão sobre a proteção e a exploração comercial da vacina contra a peste da manqueira. Nesse contexto, apresentamos o histórico relato de Alcides Godoy e Faria Filho intitulado "Sobre 
um novo processo de vaccinação contra o carbúnculo symptomatico", publicado pela Revista Médica de São Paulo, em 31 de agosto de 1908. Nele, é possível conhecer os pormenores da festejada técnica, que possibilitou a resolução de um problema de saúde e suscitou arranjos institucionais inovadores e empreendedores. Boa leitura! 


\title{
Revista Médica de S. Paulo \\ Jornal prático de Medicina, Cirurgia e Higiene \\ Diretor-Proprietário: Dr. Victor Godinho
}

Secretários: Drs. Oliveira Fausto, Theodoro Bayma e Saul de Avilez

\section{Sobre um novo processo \\ de vacinação contra o carbúnculo sintomático}

\author{
Memória apresentada ao \\ Sexto Congresso Brasileiro de Medicina e Cirurgia \\ pelos Drs. \\ Alcides Godoy e Faria Filho
}




\section{Sobre um novo processo de vacinação contra o carbúnculo sintomático*}

Memória apresentada ao Sexto Congresso

Brasileiro de Medicina e Cirurgia pelos

Drs. Alcides Godoy e Faria Filho

O presente trabalho contém fatos que foram estabelecidos no Instituto de Manguinhos no correr do ano passado, por um de nós em colaboração com o dr. Rocha Lima, em estudos comparativos feitos com o fim de verificar o valor dos diferentes meios de proteção dos bovídeos contra o carbúnculo sintomático, e em Minas Gerais, quando em comissão e em companhia dos doutores Rocha lima e Carlos Chagas, estabelecíamos o valor da vacina que experiências de laboratório nos havia feito preferir. O estudo mais aprofundado da nossa vacina, a técnica do seu preparo em grande escala, as pesquisas tendentes ao julgamento de um dado produto como vacinante, etc., foram por nós continuados este ano.

O carbúnculo sintomático é com certeza a zoonose mais importante, entre as que infectam os campos de criação do Estado de Minas Gerais, pelos prejuízos que causa. É uma moléstia peculiar aos bovídeos, raramente acometendo as ovelhas. Moléstia infecciosa aguda é causada pelo desenvolvimento nos tecidos muscular e conjuntivo de um micróbio anaeróbico ("bacilo Chauvoei", "bacilo carbonis"), ela é conhecida entre nós sob denominações diversas: "peste da manqueira", "mal do ano", "quarto inchado", etc.

Não foi, que tenhamos notícia, feito entre nós nenhum estudo bacteriológico, apenas o dr. J.B. de Lacerda diagnosticara a moléstia pelos exames clínico e microscópico e iniciara a imunização segundo o processo por ele preparado.

O material de que nos servimos para estudos foi enviado ao Instituto pelo dr. H. Villaça e devido a instância do dr. Carlos Chagas, sendo colhido um * Texto atualizado a partir do original (N.E.). 
animal espontaneamente atacado e enviado nas melhores condições possíveis. Um bezerro inoculado com o suco de um fragmento do músculo recebido sucumbira, tendo apresentado um carbúnculo típico; deste animal foi isolada a nossa primeira amostra de carbúnculo sintomático, tendo havido desenvolvimento de colônias somente nos tubos de agar a que havíamos adicionado soro de cavalo. $\mathrm{O}$ isolamento foi obtido segundo o processo de agar em camadas altas de Veilloa-Liborius. O carbúnculo sintomático naquelas condições se desenvolve $e$ de um modo inteiramente específico.

O diagnóstico do carbúnculo sintomático é extremamente simples e pode ser estabelecido por dados clínicos, necroscópicos, ou epidêmicos. A invasão rápida, quase súbita, o estado febril no início, a hipotermia no fim da moléstia, a abolição do apetite, o aparecimento de uma tumefação dura, que cresce rapidamente e que vai se tornando depressível, enfisematosa e timpânica, o caracterizam. À inspeção o vitelo morto pelo carbúnculo mostra-se tumefato, a pele achando-se distendida por gases; seccionada a pele na sede da lesão específica escapam-se bolhas de gases de um odor butírico; o tecido conjuntivo mostrase infiltrado de um líquido vermelho escuro, outras vezes simplesmente seroso, e sempre acompanhado de inúmeras bolhas gasosas. Pelo exame de frotis de suco de músculo verifica-se a presença nos pontos em que a moléstia se desenvolveu de bastonetes curtos, raramente longos, isolados, móveis, sendo o corpo microbiano ora homogêneo, ora vacuolizado; os bastonetes são cilíndricos, fuziformes ou elípticos (clostrídios), as extremidades desses elementos são sempre arredondadas, e se a autópsia não é feita logo após a morte encontram-se formas esporuladas, o esporo não tendo sede de predileção. Os clostrídios são coráveis pelo iodo em castanho ou pardo escuro, não temos porém observado a coloração azul ou violeta de que falam os autores. A moléstia ataca exclusivamente os animais de seis meses a dois anos de idade, dos acometidos raríssimos se salvando. Os animais doentes não transmitem a moléstia que tem o seu aparecimento regularmente periódico.

O bacilo do carbúnculo sintomático é de difícil cultura se não se observa nas culturas sucessivas o uso de sementes obtidas somente em meios privados de glicose e que possuam um grande número de poros. O meio tem na cultura deste micrófita a máxima importância, assim é que, como meio de escolha para a sua cultura, têm sido propostos os seguintes: caldo Martin (Leclaínche 
\& Vallée), agar com pequenos pedaços de músculo estéril em suspensão ou caldo com lactato e carbonato de cálcio (Grassberger \& Schattenfroh), soro de boi ou decocto de carne (Duenschmann), soro ou sangue (Kitt), etc.

É aos meios adicionados de soro que damos preferência. Assim empregamos conforme o fim da cultura agar simples ou glicosado, caldo simples ou glicosado, a que adicionamos uma parte de soro para três de caldo ou agar. Quando desejamos um desenvolvimento ainda mais abundante ajuntamos ao caldo simples-soro cerca de $1 / 20$ de sangue desfibrinado. Em gelatina com ou sem glicose dá-se o desenvolvimento de pequenas colônias arredondadas que liquefazem lentamente o meio. Em agar-soro as colônias são típicas, aparecendo como esferas perfeitamente regulares, grandes e de aspecto nebuloso, tendo o centro marcado por um ponto mais escuro. Estas colônias são características e servem para o diagnóstico rápido do carbúnculo sintomático. A nossa amostra sob que temos toda a garantia de autenticidade não vegeta seguidamente em meios privados de gelatina ou soro. Os meios líquidos são recobertos de uma camada de dois centímetros de espessura de vaselina líquida; este simples meio tem-se mostrado sempre suficiente para manter as condições de anaerobia no meio de cultura.

Por dois processos podemos tornar refratário a uma dada infecção, um animal sensível, ou uma inoculação no seu organismo de germes vivos ou mortos ou produtos por eles formados nos meios de cultura (imunização ativa) ou pela inoculação do soro de um animal assim tratado (imunização passiva). Na prática o primeiro é preferível não só por ser a imunidade conferida mais duradoura como mais econômico.

O estudo da imunidade no carbúnculo sintomático teve ponto de partida nos trabalhos de Arloing, Cornevin e Thomas. A vacinação tem sido obtida pela inoculação de pequenas doses do líquido do edema ou do suco do músculo em natureza em região pouco sensível ou após atenuação pelo calor, ou anti-sépticos; pela injeção de culturas atenuadas; pela inoculação de cultura ou material virulentos combinados com imune-soro; ou pela inoculação de produtos formados nas culturas; ou pelas toxinas só ou combinadas com soro específico, etc.

No processo de Arloing, Cornevin emprega-se suco de músculo virulento seco e atenuado pelo calor. Preparam-se duas vacinas; a primeira é obtida pelo aquecimento a $100-104^{\circ}$ durante sete horas, a segunda a $90-94^{\circ}$ pelo mesmo espaço de tempo. Depois de ligeira trituração são os pós fornecidos ao consumo. 
Estes pós são mais finamente pulverizados e inoculados na dose de um centigrama por animal, de preferência na cauda; a segunda sendo injetada 12 a 14 dias depois da primeira.

Kitt e Nörgaard preparam uma vacina atenuando o suco de músculo pelo calor úmido a 98-109 (Kitt) ou 94-94º (Nörgaard).

Thomas aconselha introduzir debaixo da pele da cauda ou da espádua um fio embebido de suco virulento seco.

Leclainche e Vallée indicam um processo de preparação de vacinas em pó; para isso semeiam sangue de cavalo com sangue do coração de cobaia morta de carbúnculo sintomático e após liquefação do meio este é dessecado em placas estéreis e sujeito ao tratamento aconselhado por Arloing.

Kitasato foi o primeiro que observou a atenuação de culturas pelo envelhecimento e mostrou que elas eram imunizantes, outro tanto observando com cultura aquecida a $80^{\circ}$.

Leclainche e Vallée retomaram a questão de imunização por meio de culturas puras. Pelo emprego do caldo Martin obtêm culturas muito virulentas, culturas essas que pelo aquecimento a $70^{\circ}$ diminuem consideravelmente de virulência. Os animais inoculados com essas culturas resistem à injeção de culturas virulentas, daí deduzem um método de vacinação por meio de duas inoculações; a primeira vacina sendo a cultura aquecida a $70^{\circ}$ graus durante duas horas, a segunda cultura em natureza. Julgaram os autores que uma só inoculação seria suficiente. A prática em maior escala veio mostrar que o processo podia não ser inócuo. Em trabalhos posteriores Leclainche e Vallée expóem os resultados obtidos e que levou-os a dotar a sorovacinação.

Grassberger e Schattenfroh propõem a imunização por meio de misturas neutras de toxina e antitoxina. Os trabalhos destes autores sobre toxina e antitoxina do carbúnculo sintomático ainda não receberam confirmação. $\mathrm{O}$ processo, pondo de lado a questão da imunização com toxinas compensadas, ainda é passível das seguintes objeções: falta de regras fixas para a obtenção da toxina, da propriedade de serem toxígenas não ser geral, e além disso a quantidade a inocular em cada animal é demasiado grande 15-30cc.

Passemos agora ao estado das culturas de carbúnculo sintomático em meios com glicose, sobre que se baseia o nosso método de vacinação, assunto principal deste trabalho. 
Desde o começo do nosso estudo verificamos a inocuidade das culturas em meios glicosados, e não era pela adição de sangue, que conseguimos culturas virulentas. Verificando que os animais inoculados com as culturas avirulentas tornavam-se imunes, pensamos desde logo na possibilidade de utilizá-las como vacinas. $\mathrm{O}$ estudo das culturas em meios glicosados e nos privados desse açúcar, nos mostraram a razão de ser de modo diferente de se comportarem em relação à virulência.

A cultura em caldo glicosado soro se faz a $37^{\circ} \mathrm{com}$ a viva fermentação, traduzida por uma forte produção de gases. A cultura no fim de 48 horas no máximo cessa inteiramente, os germes depositando-se o líquido torna-se perfeitamente transparente, formando-se um depósito branco amarelado, mucilaginoso. Pela agitação o depósito emulsiona-se completamente, sedimentando-se lentamente quando o tubo de cultura é deixado em repouso. $\mathrm{O}$ óleo de vaselina que recobre o meio toma uma cor verde amarelada.

O exame microscópico de uma dessas culturas, ainda em plena vegetação, mostra bacilos finos, de extremidades arredondadas, de plasma ora homogêneo, ora vacuolizado, observando-se ainda a existência de bacilos mais grossos, assim como de formas filamentosas longas e delgadas. Não é raro encontrarse clostrídios. Muito pouco micróbio possui mobilidade. Nas culturas em início os germes tomam o Gram, mas à proporção que a cultura continua vai diminuindo a proporção de indivíduos que assim se comportam. Os esporos são muito raros e o meio torna-se fortemente ácido.

Um fato se observa desde logo: é a fraca vitalidade dessas culturas, pois dificilmente se obtêm resementeiras com elas, contudo se se faz a sementeira nas primeiras 24 horas de cultura a vegetação continua. Experiências feitas nos mostraram que meios de cultura que contêm para mais de 0,5 de glicose portam-se do modo acima descrito, a quantidade de glicose sendo abaixo da acima indicada a cultura se aproxima do tipo da cultura em caldo simples-soro.

Em caldo simples-soro a cultura é de aspecto muito mais regular, nela se desenvolvendo somente bacilos perfeitos, que chegam quase todos a esporular. Os micróbios são muito móveis neste meio e coram-se uniformemente pelo Gram.

Do exame do quadro acima resulta que as culturas em caldo glicosado são sempre pouco ricas em formas vegetativas e avirulentas, enquanto que as feitas 


\section{Influência da glicose sobre a cultura do carbúnculo sintomático}

$\begin{array}{lcccccc}\text { Cultura } & \text { A } & \text { B } & \text { C } & \text { D } & \text { E } & \text { M } \\ & & & & & & \\ \text { Meio } & \text { glic. } & \text { glic. } & \text { simpl. } & \text { simpl. } & \text { simpl. } & \text { simpl. } \\ & & & & & & \\ \begin{array}{l}\text { No de esporos } \\ \text { por c.c. }\end{array} & 300 & 260 & 300.000 & 2.150 .000 & 30.000 & 250.000 \\ \begin{array}{l}\text { Reação em cobaias } \\ \text { inoc. com 3cc. }\end{array} & 0 & 0 & \text { morte } & \text { morte } & \text { viva reac. } & \text { morte }\end{array}$

em caldo simples são sempre muito ricas e virulentas quase sempre: temos ainda que o número de 30.000 por cc. provoca forte reação sem determinar a morte. Muitas outras experiências nos mostraram que a virulência de uma cultura terminada a vegetação, quando semeada com um mesmo material e dependente do número de esporos que ela contém.

Chamamos a atenção para o fato das culturas em caldo glicosado não serem tornadas virulentas pela adição de ácido láctico ou por meios desviadores da fagocitose, tais como carmim e hemácias, etc., nem pela adição do líquido claro de uma cultura virulenta centrifugada, o que faz crer que não seja a ausência de qualquer substância quimiotática negativa ou a intensa fagocitose que se segue a sua inoculação que as torna avirulenta, antes cremos que seja devido ao pequeníssimo número de formas vegetáveis, incapazes de criarem um foco infeccioso.

As culturas virulentas não perdem essa propriedade pelo aquecimento a $57^{\circ}$ durante meia hora e a conserva pelo espaço de meses, o que ainda indica que essa propriedade reside nos esporos.

O estudo do quimismo dessas culturas seria interessante para explicar o mecanismo pelo qual a glicose inibe a esporulação. Ücke e sobretudo Hibler assinalaram o fato da pequena produção de esporos em meios com açúcar ou 
glicerina, atribuindo-a ao meio se tornar pela vegetação muito ácido. Grassberger e Schattenfroh igualmente observaram a fraca esporulação nos meios glicosados. A não esporulação não nos parece dever ser referida à produção de ácidos, pois ela se observa mesmo após adição de carbonato de cálcio ao meio da cultura.

Como já dissemos, é possível conferir a imunidade pela inoculação dessas culturas. A imunidade adquirida pelas cobaias contra a inoculação de culturas virulentas não é absoluta, sendo que pela inoculação de prova elas sucumbem em proporção de $20-50 \%$. Nos bovídeos a imunidade é muito mais sólida, pois não tivemos ainda nenhum que, tendo sido inoculado com culturas avirulentas, não resistisse à inoculação de prova, que matava testemunhas em dois a três dias.

Não podemos terminar esta parte do nosso trabalho sem chamar a atenção sobre o possível, se bem que raro, desenvolvimento atípico das culturas em caldo glicosado-soro, desenvolvimento que se caracteriza pela vegetação nesse meio como se aí não existisse açúcar. As culturas assim obtidas são virulentas como demonstra o desastroso ensaio de imunização que fizemos na Fazenda do dr. Constantino Palleta, em Juiz de Fora, fato já referido em comunicação à Sociedade de Medicina e Cirurgia de Juiz de Fora, e publicado no Brasil Médico pelo doutor Rocha Lima. Em 26 vitelos inoculados nessa ocasião morreram oito. Evidentemente essas culturas são imprestáveis para a vacinação.

Em relação ao mecanismo da imunização, só podemos dizer que a fagocitose representa aqui um papel de máxima importância. A reabsorção dos germes inoculados faz-se por intermédio dos leucócitos que se segue a vacinação. Se os esporos introduzidos germinam ou não, não podemos ainda dizer com segurança, entretanto é mais plausível a segunda hipótese, visto ser impossível pela inibição da fagocitose determinar-se o aparecimento da moléstia. A vacinação contra o carbúnculo sintomático provoca, com certeza, o aparecimento nos humores dos animais vacinados de substâncias análogas às substâncias bacteriotrópicas de Neufeld ou opsoninas de Wright. Sobre o poder bactericida do soro dos animais assim tratados não temos ainda experiências seguras.

Transcrevemos agora os resultados obtidos por alguns dos criadores que têm empregado a nossa vacina e tiveram a bondade de nos informar dos resultados.

O sr. Tertuliano Braga, fazendeiro em Guarany (Minas Gerais), comunica-nos que dos 69 vitelos que vacinamos na sua fazenda, nenhum adquiriu a 
moléstia e dos cinco que deixamos de vacinar dois morreram, o que o levou a vacinar os três restantes.

O sr. Orosimbo de Castro, fazendeiro em Tartária (Minas Gerais), inoculou 126 vitelos e deixou de inocular dois que morreram algum tempo depois de carbúnculo, sendo de notar que os vacinados conservaram-se indemnes. Faznos notar que a perda anual por carbúnculo era de 40-50\% dos vitelos.

Da mesma zona, o sr. Henrique R. da Silva Castro fornece-nos as notas seguintes: antes da vacinação a mortalidade era de 7-8\%, em 1.369 vacinaçôes que fez não observou incidente nenhum consecutivo a elas. Em um lote de 126 vitelos guardou dois sem vacinar, morrendo estes meses depois. Os vacinados nada sofreram.

De várias outras observaçôes do mesmo gênero concluímos que a vacinação pôde ser feita mesmo nas zonas mais contaminadas sem perigo e que uma só inoculação permite aos animais atravessarem indemnes a idade de maior sensibilidade.

Não tivemos ainda um só caso em que se responsabilizasse a nossa vacina por acidentes ou perda de animais inoculados. Sendo já de muitos milhares o número de vacinação com o acometimento da moléstia foi duas ou três vezes observado, esta coincidência é expressa pelo fato da morte do animal se ter dado 24 a 48 horas após a vacinação, enquanto que pela inoculação mesmo das culturas as mais virulentas só obtemos a morte no terceiro dia da moléstia.

O número de doses fornecidas pelo Instituto foi em:

$$
1906-11.510
$$

1907 (até agosto) - 16.276

neste total de 27.780 não estando incluído o grande número de doses que empregamos a título de experiência.

Julgamos útil para facilidade da reprodução dos fatos acima referidos dar algumas indicações sobre o preparo da vacina. A vacina contra o carbúnculo sintomático, fornecida pelo Instituto de Manguinhos, é uma cultura do bacilo sintomático obtida em caldo glicosado-soro, o soro entrando na proporção de 
$1 / 3$ ou $1 / 4$. O caldo é preparado pela maceração a quente de 500 grs. de carne em 1 litro d'água a que se adiciona 10 grs. de peptona, 5 grs. de sal comum e 20 grs. de glicose. O meio é alcalinizado um pouco além do ponto de neutralidade do tournesol. O soro é colhido segundo a técnica habitual, pela sangria asséptica de cavalos. As culturas são feitas em balōes de dois litros de capacidade, sendo o meio recoberto simplesmente de vaselina líquida para que se dê a vegetação. A sementeira é feita com uma cultura, evidentemente verificada quanto à pureza e muito rica em esporos, os balóes semeados são colocados na estufa a $37^{\circ}$ onde se deixa terminar a vegetação, cerca de 48 horas. Terminada esta, procede-se à verificação em relação à pureza, à abundância, à riqueza em formas vegetativas, à virulência, etc., sendo, então, se se verifica que os seus caracteres correspondem aos de uma cultura típica, distribuída em vidros de 10 cc., fechados a lâmpada, que são rotulados e acondicionados em caixinhas de madeira depois de envolvidos na seguinte bula:

\section{Instruções para o emprego da vacina contra a peste da manqueira}

A vacina é fornecida sob a forma de um líquido turvo, que clareia pelo repouso, formando-se um depósito branco amarelado.

Nos frascos fechados, em que é fornecida, a vacina conserva-se inalterada por muitos meses. Aberto, porém, um frasco deve ser usado no mesmo dia.

A vacina deve ser empregada por injeções debaixo da pele, na dose de 2cc. Não se deve empregar dose menor do que esta. Nesta dose a vacina é completamente inócua e, antes de ser fornecida, é experimentada em animais do Instituto, empregando-se doses muito maiores do que a acima indicada. Só pode haver acidentes em animais que, na ocasião da injeção, já se achem atacados da moléstia, embora sem os sintomas.

A vacinação deve ser repetida de cinco em cinco meses, fazendo-se a primeira inoculação quando o bezerro tem cinco meses de idade.

\section{Modo de Usar:}

Agitar o frasco.

Partir a sua extremidade afilada.

Introduzir, pela abertura assim obtida, a agulha de uma seringa própria 
para injeções, e aspirar a vacina. Expelir voltando a seringa para cima o ar que tenha penetrado na ocasião de aspirar.

Lavar com uma solução de creolina o ponto de inoculação, que é de preferência o quadril.

Imobilizar bem o animal. Introduzir a agulha sob a pele cerca de 2 a 2 centímetros e inocular a dose acima indicada, isto é, 2 cc. que correspondem à quinta parte do conteúdo de cada frasco.

A vacina traz um número e uma data que devem ser indicados em qualquer comunicação ou reclamação. Estas devem ser dirigidas para o Instituto de Manguinhos - Caixa do Correio 926 - Rio de Janeiro.

\section{Conclusões}

1. A vacinação por meio de culturas é a única possível de uma verificação científica.

2. As côlonias em agar-glicosado-soro são típicas e servem para o diagnóstico rápido do carbúnculo sintomático.

3. As culturas de carbúnculo sintomático em caldo glicosado-soro são aviruladas.

4. As formas microbianas aí existentes são inaptas à vegetação.

5. O estado refratário ao carbúnculo sintomático é fácil de ser conferido.

6. A imunização dos bovídeos é mais fácil que a das cobaias.

7. As propriedades vacinantes das culturas dependem da massa microbina aí existente.

8. A inocuidade dessas culturas é independente da existência de substâncias quimiotacticas negativas.

9. A vacinação do carbúnculo sintomático por uma substância absolutamente inócua, é certamente realizada pela inoculação de culturas típicas em caldo glicosado-soro. 
10. São responsáveis pelos casos de carbúnculo sintomático consecutivos à vacinação, o método de preparo da vacina ou o processo de vacinação.

11. A virulência de uma cultura de carbúnculo sintomático terminada a vegetação é no mesmo meio e com a mesma semente dependente do número esporos.

12. A imunidade adquirida pelos vitelos vacinados é suficiente para que eles atravessem indemnes a época de maior sensibilidade.

13. Uma única inoculação é suficiente para conferir a imunidade.

Rio de Janeiro, 4 de setembro de 1907. 